\title{
Measurement of Pre- or Post-Filter-Ionised Calcium Concentration during Continuous Veno-Venous Haemofiltration
}

\author{
Chris Anstey ${ }^{a-c}$ \\ ${ }^{a}$ Department of Intensive Care Medicine, Nambour Hospital, and b Sunshine Coast Institute for Critical Care \\ Research, SCHHS, Nambour, Qld., and 'School of Medicine, University of Queensland, Brisbane, Qld., Australia
}

\section{Dear Editor,}

Thank you for publishing the results of our recent prospective, randomised, controlled study and for the commentary by Jacobs et al. in the same issue $[1,2]$. In that commentary, the authors raise the issue of the measurement and control of postfilter-ionised calcium concentrations as a means of enhancing filter survival.

When we first began using regional citrate anticoagulation as our preferred method of continuous renal replacement therapy approximately 9 years ago, we were using a proprietary $14 \mathrm{mmol} / \mathrm{l}$ pre-filter substitution solution as regional citrate anticoagulation for a continuous veno-venous haemofiltration circuit at a rate of $2,000 \mathrm{ml} / \mathrm{h}$ [3]. At that time, we sampled post-filter blood for both clearance studies and adequacy of anticoagulation and invariably found that the post-filter $\left[\mathrm{ICa}^{2+}\right]$ was less than $0.5 \mathrm{mmol} / \mathrm{l}$ and that our circuits lasted well. Since then for both purely practical safety reasons around the issues associated with drawing blood from a pressurised circuit using a sharp needle and in accordance with the local Health Department policy around preventing needle stick injuries [4], we have largely abandoned the practice. We do, however, continue to monitor serum-ionised calcium regularly by safely drawing blood from the indwelling intra-arterial cannula circuit and replace both calcium and magnesium as necessary [1].

With the local discontinuation of the $14 \mathrm{mmol} / \mathrm{l}$ citrate solution and the subsequent use of first an $18 \mathrm{mmol} / \mathrm{l}$ and now a $15 \mathrm{mmol} / \mathrm{l}$ citrate solution, we see no practical requirement to sample post-filter blood; we, however, agree that such measurement may be necessary in the context of poor filter survival, for example, less than $24 \mathrm{~h}$. At present, using a $15 \mathrm{mmol} / \mathrm{l}$ solution, our filters have a median survival of $66 \mathrm{~h}$ [1].

Our study was primarily concerned with the biochemical abnormalities associated with the different electrolyte compositions of the 2 fluids, notably the occurrence of a non-respiratory alkalemia with the $18 \mathrm{mmol} / \mathrm{l}$ solution. It also dealt with the effect that those differences had in patients over time - in those who were functionally anephric and hence unable to renally compensate for disturbances in their major extracellular electrolytes $[1,3]$. In our study, filter survival was an interesting but only a secondary concern.

Finally, on an issue related to the use of citrate as an anticoagulant, I am motivated to make a remark. It is an erroneous and common misconception to state that citrate is metabolised to bicarbonate. In the Krebs Cycle, citrate is metabolised to carbon dioxide with the coproduction of NADH [5].
According to the tenets of the strong ion theory, any change in bicarbonate concentration is a result of secondary dissociation of carbonic acid in accordance with the law of mass action and the principle of macrocompartment electroneutrality and not as a result of primary metabolism [6]. In the plasma compartment, this defence of electroneutrality occurs as a consequence of perturbations in the concentrations of the major strong ions (sodium, chloride and Llactate $\left(\mathrm{pKa}=3.79\right.$ at $\left.\left.25^{\circ} \mathrm{C}\right)\right)$ and the significant weak acids (albumin and inorganic phosphate). In our study, the non-respiratory alkalemia that occurred over time in the $\mathrm{C} 18$ group was due to the widening of the apparent strong ion difference (SIDa) as a result of the equilibration of the extracellular fluid over time with a high sodium content exogenous fluid $(152 \mathrm{mmol} / \mathrm{l})$ in patients who could not handle an excess sodium load because of renal failure. In the context of the assessment of a non-respiratory alkalemia, the use of SIDa is preferred over that of $\mathrm{pH}$ because of the co-dependency of $\mathrm{pH}$ and $\mathrm{PCO}_{2}$. Plasma chloride concentration remained within normal limits in both groups throughout. The presence of hypoalbuminemia also contributed to the significant non-respiratory alkalemia in the C18 group and the minor non-respiratory alkalemia in the $\mathrm{C} 15$ group.

\section{KARGER}

(c) 2016 S. Karger AG, Basel

E-Mail karger@karger.com

www.karger.com/bpu
Chris Anstey

Director, Department of Intensive Care Medicine, Nambour Hospital

Sunshine Coast Institute for Critical Care Research, SCHHS

PO Box 547, Nambour, QLD 4560 (Australia)

E-Mail chris.anstey@ health.qld.gov.au 


\section{References}

1 Anstey C, Campbell V, Richardson A: A comparison between two dilute citrate solutions (15 vs. $18 \mathrm{mmol} / \mathrm{l}$ ) in continuous renal replacement therapy: the base excess and renal substitution solution study. Blood Purif 2016; 42:194-201.

2 Jacobs R, Honore PM, Hendrickx I, Spapen HD: Regional citrate anticoagulation for continuous renal replacement therapy: all citrates are not created equal! Blood Purif 2016;42: 219-220.

3 Gutierrez-Bernays D, Ostwald M, Anstey C, Campbell V: Transition from heparin to citrate anticoagulation for continuous renal replacement therapy: safety, efficiency, and cost. Ther Apher Dial 2016;20:53-59.

4 Health.qld.gov.au:Queenslandhealth policyon prevention ofneedlestickinjuries.https://www. health.qld.gov.au/clinical-practice/guidelinesprocedures/diseases-infection/infection-prevention/standard-precautions/sharps-safety/ needle-stick-injuries/default.asp.

5 Krebs HA: The intermediate metabolism of carbohydrates. Lancet 1937;230:736-738.

6 Stewart PA: Modern quantitative acid-base chemistry. Can J Physiol Pharmacol 1983;61: 1444-1461. 